\title{
An Evaluation of TS13298 in the Scope of MoReq2
}

\author{
Gülten Alır ${ }^{1}$, Thomas Sødring ${ }^{2}$, and İrem Soydal ${ }^{3}$ \\ ${ }^{1}$ Aksaray University, Faculty of Education, Aksaray, Turkey \\ gulten.alir@aksaray.edu.tr \\ ${ }^{2}$ Oslo University College, Faculty of Journalism, Library and Information Science, \\ Oslo, Norway \\ thomas.sodring@jbi.hio.no \\ ${ }^{3}$ Hacettepe University, Department of Information Management, Ankara, Turkey \\ soydal@hacettepe.edu.tr
}

\begin{abstract}
TS13298 is the first Turkish standard developed for electronic records management. It was published in 2007 and is particularly important when developing e-government services. MoReq2, which was published in 2008 as an initiative of the European Union countries, is an international "de facto" standard within the field of electronic records management. This paper compares and evaluates the content and presentation of the TS13298 and MoReq2 standards, and similarities and differences between the two standards are described. Moreover, the question of how MoReq2 can be used as a reference when updating TS13298 is also dealt with. The method of hermeneutics is used for the evaluation, and the texts of TS13298 and MoReq2 were compared and reviewed. These texts were evaluated in terms of terminology, access control and security, retention and disposition, capture and declaring, search, retrieval, presentation and metadata scheme. We discovered that TS13298 and MoReq2 have some "requirements" in common. However, the MoReq2 requirements, particularly in terms of control and security, retention and disposition, capture and declaration, search and presentation, are both vaster and more detailed than those of TS13298. As a conclusion it is emphasized that it would be convenient to update TS13298 by considering these requirements. Moreover, it would be useful to update and improve TS13298 by evaluating MoReq 2 in terms of terminology and metadata scheme.
\end{abstract}

Keywords: TS13298, MoReq2, electronic records management standards.

\section{Introduction}

The phenomenal increase in the amount of electronic information that is being generated has made the problem of information management a current issue. In a study carried out by the Association for Information and Image Management [1], some notable results regarding the issue of information were presented. According to the study, while there was an increase in the number of print records in $56 \%$ of the organizations surveyed, there was a decrease in the number of such records in $22 \%$ of the organizations. The report found that the number of electronic records had also increased in $70 \%$ of the organizations, without a corresponding decrease in the number of such records in any of the organizations. This shows a trend that the overall 
amount (print and electronic) of records being generated is increasing while the amount that are print based is decreasing and the amount of electronic records is increasing. According to the same study, $37 \%$ of organizations are scanning over half of their incoming (print) documents and $12 \%$ of organizations scan more than $80 \%$ of incoming (print) documents. Many of the organizations $(60 \%)$ that do not use an electronic records management system (ERMS) are experiencing problems with electronic records management. These organizations do not feel confident about the security of their records in terms of change, deletion or inappropriate access [1].

The applications used in the public sector (in particular) must support the policies governing freedom of information, while efficient information sharing is dependent on the use and evaluation of reliable information. In addition to this, success in basic essential operations must be achieved such as ensuring the reliability and legal validity of records, as well as data protection. However this is dependent on supporting the organization with an effective electronic records management. A sound structured operation of public management can only be realized with the support of records management. A sound records management system is the foundation for transparency within the state, and also an important factor for the state to be able to perform its responsibilities [2], [3], [4].

Records management operations have developed in line with technological innovations and have only recently been evaluated within the archive discipline. Efforts made by national and international societies in recent years have gained a new dimension with the procedures, standards, and applications that have been developed. Electronic records management standards have been established based on research by both national and international organizations. As a result of these standards, there is a general expectation of increased efficiency by public organizations in their e-government operations. This will be achieved by providing uniformity of the data structures, providing information/data interchange at national and international level, and by developing documentation that will instruct organizations generating electronic records and software developers within the field of records management.

It is inevitable that standards need to be reviewed, updated, and harmonized with the new conditions and situations over time. Standards do have a life cycle as well and can never be considered to be complete [5]. Waalwijk [6] also underlines that standards only have a limited lifetime and need to be revised.

Turkey also needs to maintain its efforts and work in the field of electronic records management which started with e-government applications. It is also crucial to update the standards, the most significant part of these efforts, in line with international and technological developments. Employed for the establishment of TS13298 ${ }^{1}$, MoReq has a significant place with its updated new version. Particularly, such a standard supported by the European Commission is also significant for Turkey aiming at adopting the European Union norms in the long term to act in line with developments in Europe.

MoReq2 (Model Requirements for Management of Electronic Records) is the result of a study to which numerous experts from different disciplines contributed. Moreover, it has been taken as a basis by several countries for developing their national standards. MoReq2 has not been prepared for any commercial purpose or

${ }^{1}$ In this study the term "TS" stands for "TS13298". 
according to the needs of any particular country or organization, which increases its applicability for international development and acceptability of the standard for national applications.

The purpose of this study is to evaluate the TS standard, which plays a key role in electronic records management in Turkey, within the framework of the MoReq 2 standard. Moreover, the aim of the study is also to give a clear overview of the similarities and differences of the two standards, and to present recommendations for additions, arrangements, and updates which can be introduced into TS. The scope of MoReq2, which is a model document, is much wider than TS. On this point, it is considered whether MoReq2 with more developed specifications can make contributions to the development of TS or not. Taking specifications and content of an internationally accepted standard as a reference will present a definite advantage in terms of time and effort. MoReq [7] was used when developing TS. Therefore, it is of great importance to evaluate the developments in MoReq2 against TS. The aim of this study is to increase awareness concerning the developments in MoReq2.

\section{Standards and Records Management Standards}

A standard is defined as a "document, established by consensus and approved by a recognized body, that provides, for common and repeated use, rules, guidelines or characteristics for activities or their results, aimed at the achievement of the optimum degree of order in a given context" [8]. There are two types of standards [9]:

- De jure standards: those officially issued by governments or standards bodies.

- De facto standards: those not issued by such bodies but nevertheless considered valid standards because they have been widely adopted by a community of users.

Standards, technical reports, guidelines, and white papers create a professional environment of "best practice" procedures. The purpose of standards is to ensure conformity among products in all countries where companies developing those products do business. The first priority with regards to users is to ensure high quality and performance in goods and services. Products developed against standards ensure interoperability between the competing organizations, and objective criteria, on which agreement is reached, can be used when defining and testing quality. At the same time, safety, consistency, uniformity, reliability and economic efficiency can be ensured with standards. Standards and guidelines are fundamental reference tools not only for the development of specific tools, but also for ensuring and maintaining quality in non-concrete fields such as the content of information and workflow. Standards also allow companies to agree on common values that can cross local, national and even international lines [10], [11]. Like the other disciplines of the information management field, records management is affected by developments in information technologies. New standards are established, the existing ones are developed and management and system approaches consistent with standards are adopted. Public and voluntary organizations have started to develop standards, and to use physical and managerial systems, for various reasons, such as requirements as a result of the development of e-government applications 
(freedom of information act, data protection act, etc.), or the fact that there is a need to increase the efficiency and quality of information management while decreasing its costs.

Hofman [12] states that records management standards will raise the level of professionalism as well as the level of authority, and will provide organizations as well as the records management profession with a comprehensive framework.

Public organizations such as the International Standards Organization (ISO), American National Standards Institution (ANSI) and voluntary organizations, such as ARMA International, International Council of Archives (ICA), Document Lifecycle Management Forum (DLM Forum) have carried out international studies on establishing records management standards. While some of these standards are mainly about specific issues, namely preservation, e-mail management, metadata ${ }^{2}$, some of them cover records management applications and general procedures. For instance, "ISO 15489 Information and documentation -- Records management" [13] is the first international standard where general procedures in records management are underlined [14]. It has provided the very basis for various national and international standards in the field of records management for determining common requirements of terminology, characteristics of records, records management process, and workflow.

MoReq [7] is the first international standard covering functional requirements/specifications expected to be available in specialized software required for establishing Electronic Records Management Systems (ERMS). MoReq has guided various national standards and has been translated into several languages.

\subsection{Model Requirements for the Management of Electronic Records (MoReq2)}

MoReq2 was created by DLM Forum (Document Lifecycle Management Forum) through an initiative of European Commission countries. Established in 1997, DLM Forum has been an independent organization since 2002. The main purposes of the DLM Forum include "to establish a strategic network to bring together individuals and organizations, from both the public and private sector involved in Document Lifecycle Management; ... to raise awareness in the field of Document Lifecycle Management; to provide technology and knowledge transfer and information services, appropriate practice guidelines, benchmark indicators and information, educational, skills development and research opportunities" [15]. Although founded as a European-centric organization, DLM Forum is available for all organizations and researchers from all around the world.

MoReq was developed by DLM Forum and published in 2001. It was composed of 390 requirements and 100 pages [7]. Due to technological advancements, this document needed to be improved and updated. As a result of the research that was undertaken, a new version of MoReq called MoReq2 was published in 2008 [16]. The development in MoReq2 is qualified as an "evolution" in the literature. MoReq2 provides an approach for the implementation of records management principles independent from any format or system. Some of the around 800 requirements in MoReq2

\footnotetext{
${ }^{2}$ For detailed information, http: / / www. ica.org/en/standards, http://www.arma.org/standards/index.cfm, http://www.iso.org
} 
are mandatory, while some of them are only optional. ${ }^{3}$ MoReq 2 has been established as a superset, which can meet requirements of a big organization at maximum level. Thanks to its modular structure, organizations with small structures can also make use of the requirements of the sections needed as well. Some sections of MoReq2 (Sections 3 to 9) contain the core ERMS functional requirements in detail. Section 10 is defined as an "Optional Module". Some of these sections will be essential for some organizations, but unnecessary for others. In this way, added value is provided by taking into consideration the needs of organizations with different dimensions, "Section 11" contains non-functional requirements and "Section 12" identifies requirements for managing metadata [16].

An ERMS may be certified MoReq 2 compliant by an accredited MoReq2 test centre. Among the characteristics of MoReq2 there are testability, metadata scheme and XML scheme. MoReq2 was designed and written with testability, and testing materials have been developed and published alongside the electronic copies of the requirements. The Metadata scheme of MoReq2 is much more detailed than MoReq in terms of both scope and presentation. Each data element is expressed in tables in MoReq2 where 158 unique metadata elements are defined. The name of the metadata element, its obligation status and definition, whether more than one value is allowed for the element (occurs), how the value(s) for this element are produced (populated), the suggested default value (default), rules for the inheritance of the metadata values (inheritance), conditions and rules that govern the use and value(s) of the element (use conditions), references to formal requirements (requirements) from MoReq 2 that can change values of the metadata element, etc are described in detail [17]. The XML scheme developed in MoReq 2 provides a way for electronic records, with their metadata, to be transferred between systems without loss of their functionality. A significant advantage of MoReq 2 is that countries can make translations and amendments in accordance with their own languages, terminologies, and laws in the section called "Chapter 0". MoReq [7] has been a model for various national standards, and 10 countries have published this standard in their own languages. Moreover, it is one of the reference documents used for the development of TS and NOARK5 [18]. MoReq2 had also been translated into four languages (French, Russian, Czech and Slovenian) as of January 2010 [19].

In spite of these developments, criticisms of MoReq 2 focus on the fact that it highly detailed and long and that it may be problematic for small companies to cover the cost of meeting these requirements [20], [21]. Indeed, the reason why this document is so long and detailed is that it has been prepared foreseeing at the highest level the possible challenges of a large system. However, it also covers specifications to meet the requirements of small-sized organizations. MoReq2 continues to be developed taking into consideration the various criticisms against it. Among the $2010 \mathrm{ob}-$ jectives stated by DLM Forum December 2009, is the establishment of a core module composed of mandatory requirements [22].

\footnotetext{
3 "MoReq2 contains both mandatory and desirable requirements. This level of mandation is indicated as follows:

- the word "must" indicates that a requirement is mandatory;

- the word "should" indicates that a requirement is desirable."

In all cases, the level of mandation is dependent on its context" [16].
} 
MoReq2 is an independent document prepared with the contributions of several experts from various countries and disciplines, supported by the European Commission, dealing with the requirements of both public and also private organizations in detail. This and other similar characteristics of the standard bring out the question of "national standards or MoReq2" for several countries of the European Union and other countries. As stated in MoReq2 as well, countries have their own peculiar laws, characteristics, records management traditions and needs. However, these specifications do not pose any obstacle to evaluating or adapting the document presented by MoReq2. As a matter of fact, as stated above, certain countries have already translated MoReq2 into their own languages. Moreover, there are various studies in which MoReq is compared to national standards in the literature. In these studies, generally a method based on evaluating the texts is employed, and in some studies there are interviews with the persons dealing with the issue.

Wilhelm [21] has evaluated the differences between TNA 2002 of the United Kingdom and MoReq2. At the same time, he has carried out interviews with at least one representative of each of the key stakeholders in order to discover their opinions. According to the study, MoReq2 has similarities with TNA 2002 in terms of content, structure and expression, but MoReq2 provides clear and unambiguous definitions particularly of ERMS and optional modules, and provides a more up to date, comprehensive content. However, there are criticisms that the objective of the standard is too large, and that therefore the length of the document is problematic, and that it covers too numerous requirements.

Wilhelm [23] has also evaluated the interviews for the comparison of MoReq2 and TNA 2002. He pointed out that the most significant problem concerning the implementation of MoReq2 is that it is a highly detailed and long text.

A similar study was carried out by Henttonen [24]. Henttonen compares MoReq2 and Finnish SÄHKE specifications to see their differences and similarities. The study, carried out by comparing the texts of the two standards, seeks to find out whether there is an easy way to harmonize them. According to the conclusion of the study, MoReq and SÄHKE have considerable differences in terms of data models, elements and functional requirements. In spite of some similarities, MoReq2 is more technical and detailed than SÄHKE, and the two standards are quite incompatible. However, as a conclusion, Chapter 0 of MoReq2 is referred to and it is emphasized that MoReq2 can meet the needs at national level if SÄHKE is abandoned.

On the other hand, while Waalwijk [6] gives an account of the establishment process of the requirements for electronic records management within the Netherlands Institute for Standardization, he underlines the place of MoReq in this process and makes comparisons between MoReq, ReMANO and the Core model. The study pointed out that ReMANO and the Core model were taken as the basis in developing Netherlands standard NEN 2082, and that MoReq needed to be developed and reviewed as soon as possible and to be published once again as MoReq2. 


\subsection{TS13298 Information and Documentation-Electronic Records Management}

The idea of preparing a document which will guide the organizations for the electronic records management in Turkey emerged in line with e-government work. The study mentioned in Article 37 of the "e-Transformation Turkey Project 2005 Action Plan", was presented to the public for comment for the first time in 2005 as "Reference Model of Electronic Records Management System Requirements (v.1.0)".

The document is arranged as a standard inline with the recommendations and issued as a Turkish standard in 2007 [25]. The standard is an important source for both organizations and software companies as it defines the records management requirements, and includes instructions regarding the freedom of information act and e-signature law. It also underlines the importance of building awareness in the field of records management and of pursuing the policy of records management within all units of an organization. In compliance with the regulation dated 16 July 2008, governmental institutions are required to adapt their electronic records management system in accordance with TS [26]. The text of the standard document, produced for defining functional specifications required to be available in ERMS software, is composed of 42 pages and three sections: system requirements, record requirements and metadata scheme. The main subjects such as classification, retention schedule, registration operations of electronic records, specifications for use, access control and security, and system design, are covered in the first section. In the records criteria section, there are records specifications, document management, non-electronic systems, and digital scanning systems. The last section covers metadata elements. It is composed of 93 metadata and requirements listed in 11 articles. There is no information concerning whether metadata is mandatory or optional. However, the requirement on general specifications (TS11.1.d) ${ }^{4}$ states that "The system manager will be able to determine whether metadata elements are mandatory or optional in an ERMS system and whether these elements will be indexed or not during the system design stage".

\section{Methodology}

The hermeneutics method was employed in comparing TS and MoReq2. According to Walker, the hermeneutics study "....attempts to make meaning of words and narrative and to gain understanding, it is a powerful tool for studying intact text. Methodologically, the different sources of data were analysed using a selective reading approach" [cited in 27]. Cole and Avison [28] defined the hermeneutic method process as

A piece of text is read several times asking: what statement(s) or phrase(s) seem particularly essential or revealing about the subject's prejudices and/or the phenomenon or experience being described?...Concepts help to maintain the focus of analysis on the circular presupposition of hermeneutics (that the whole precedes the determinant of the details and through

\footnotetext{
${ }^{4}$ The section and subsection names and the requirements will be mentioned either with the initials of TS (for TS13298) or with the initial of M (for MoReq2) further on in the text, in order to be able to distinguish these standards more easily.
} 
the details we construct the whole). They also help to integrate different data sources by treating them as a singular totality. [28]

There are studies in the literature where ERMSs are compared employing hermeneutics method [21], [23], [24].

In the light of this method, comparing and evaluating MoReq 2 and TS is based on the texts of these two standards. When evaluating the standards, primarily their general specifications were taken into consideration, read, and the sections to be compared defined. These sections, the subsections under each section, and requirements listed under subsections were read many times and compared. As it is not possible to specify all sections and requirements individually within the scope of this study, certain sections and requirements of particular importance for the subject, were dealt with.

TS and MoReq2 were evaluated comparatively with regard to the requirements under the sections of content, terminology, access control and security, retention and disposition, capture and declaring, searching, retrieval and presentation and metadata scheme (see Appendix). The sections were defined taking into consideration the purposes of the documents with regard to general scope, form of expression of the requirements, approach to the subject, and presentation specifications, and also samples were given with respective requirements. The study also addresses the question "Are there any specifications of TS which need to be improved and/or updated compared to MoReq2?”.

\section{Findings and Discussion}

The TS is composed of 42 pages and three sections. It is stated in the document that the standard defined "the minimum functional requirements which need to be present in ERMS software". As there is no expression to the contrary, it will be useful to evaluate all requirements in the document as mandatory. Moreover, definitions regarding the records specifications are given in the second subsection of the standard (TS7.1). However, only six terms were defined for the terminology section of the standard and for the definitions of other terms, references were made to ISO 5127 and 15489. This structure of the document leads to ambiguity.

MoReq2 is composed of 207 pages and eleven sections. The first two sections cover information and terminology with regard to the standard. Moreover, it is supported with an XML scheme. In the second section of MoReq2, there are detailed definitions under the "2.1.Key Terminology and 2.2.Key Concepts" subsections, and there is an extensive glossary (13. Reference Model) in the last section.

Controls and security: TS gives the definitions of user roles and groups in access control and security, and presents requirements of basic definitions suitable for these roles. In both standards, emphasis is laid on having access restrictions suitable for the user roles and the authority of administrator/system administrator. As for TS, with the "TS5.2.a, TS5.2.b, TS5.3.b, TS5.4.a, TS5.5.a, TS5.7.f" requirements authorization is given to the system administrator. In MoReq2, the explanations of user roles and access 
are given in subsection "4.1.Access" and mainly define in detail the authorizations of the role defined as "administrator". In this subsection, 14 of the 24 requirements are within this scope. Considering TS as a national standard, the access rights for the records and user roles (system administrator, records manager, etc.) are defined at a minimum level. This supports the purpose of the document regarded as a guide for organizations, which are to meet the minimum requirements. However, defining the authorizations of the administrator in a certain manner with regard to such a subject is important. In these types of standards, there have to be requirements leaving no ambiguity with regard to role definitions and responsibilities. The table available in MoReq2, which explains the user roles, [16] proves very useful for defining authorizations.

Audit trails evaluated within the control and security section allow for recording of the user and administrator roles in the system and their activities. "Audit" is available in subsection "TS5.9" in TS. TS employs simpler and clearer expressions than MoReq2. Requirements for changing MoReq2 audit trail configurations (M4.2.4) and recording these parameter changes (M4.2.5) are defined as well. However, MoReq2 also provides significant requirements for exporting data on any element or user stored in audit trail in a safe manner (M4.2.15). In MoReq2, requirements concerning backup and recovery, which will allow recovery of records if any are lost because of system failure or accident (M4.3), and vital records, which are considered absolutely essential to the organizations, (M4.4) are stated under various sections. As for TS, the issue of storing the data is addressed (TS6.4), but no requirement concerning backup is given. Only under the document management section with the subsection " 8.5 Storage and Backup", is there a single requirement which states "Electronic documents must be copied in safe storage and back-up units".

Retention and disposition: One of the most important elements of a records management system is retention and disposition. These operations, which need to be performed in accordance with a policy, must be addressed fastidiously. The retention schedule of TS (TS2) is composed of six subsections. In the general rules, there are 11 requirements in total concerning defining a retention schedule during the system installation, reporting and disposition function, role of records manager, association with class, elements of retention schedule, automatic notification. The storage times subsection (TS2.4) is composed of two requirements, which offer some alternatives for the beginning dates, as well as the minimum and maximum durations for the storage time of the records. Moreover, under this subject there are also certain definitions such as hierarchy of classification (TS2.2), criteria of retention and disposition process (TS2.5).

MoReq2 defines the retention and disposition subject in a detailed manner avoiding any confusion. The administrative role for changing or deleting a retention and disposition schedule (audits and metadata) is clearly defined (M5.1.8, M5.1.23). Furthermore, the requirements concerning data transfer are listed under subsection "5.3.Transfer, Export and Destruction" in MoReq2. As for TS, the requirements concerning collective transfer operations are stated without any detail with two requirements listed under electronic records registration operations (TS3.1.s, TS3.1.t).

Capturing and declaring records: The process of capturing the records means not only inserting the records into the system, but also making necessary definitions for 
the short and long term preservation of the records. Registration of records covers important stages such as the mapping of records to its classification scheme, definition of access rights, etc. Importance is attached to this issue in both standards (TS3. Capturing of electronic records, M6.Capturing and declaring records), but details of MoReq2 once again come to the fore. Both standards underline the fact that the system must support all types of records. Ten of the requirements of MoReq2 listed under the section of "Capturing and Declaring", are common to some requirements in TS3, such as capturing of electronic records (M6.1.1/TS3.1.c), components (M6.1.3/TS3.1.d), metadata requirement (M6.1.11/TS31.d). While MoReq2 gives each condition as a separate requirement, more than one requirement is joined under a single statement in TS. This also applies to the specifications listed under requirements. While MoReq2 avoids revealing the names of the file formats which can be included in the system, it gives a general list of record types which are frequently used (M6.1.1). These lists may be useful for the system designers to know more about the existing record varieties. There is no such general list in TS. Requirements concerning metadata, audit trial (M6.1.6, M6.1.9, M6.1.14, M6.1.17, M6.1.18, M6.1.21, M6.1.22) and keyword definition (M6.1.23-28) are defined in detail in "6.1: Capture" subsection of MoReq2.

E-mail management: E-mail is another significant type of document for organizations. There are certain problems both in transferring them to ERMS and in defining e-mail messages, which have different components than known record specifications. Both standards present alternatives for transferring e-mails (TS3.4.a/ M6.3.3). While MoReq2 specifies 18 requirements for definitions of metadata and the process of transferring them to the system in addition to these alternatives, TS simply states that e-mails must have a format, in which owners of e-mail addresses can be easily understood.

Scanning and Imaging: The operation of digitizing records which are not in electronic format, and transferring them to ERMS is given in the subsection "6.5.Scanning and Imaging" in MoReq2. In TS, these operations are given in the second section "Record Criteria" with the section "10. Digital Scanning Systems". TS mainly focuses on the digitization specifications of the records transferred to digital form which are originally produced in print form. While both standards declare common requirements for not limiting the system to certain formats, TS also specifies some resolutions that are suitable for different types of materials, coloring options, common file formats and their specifications (TS10.4, TS10.5, TS10.9). Similarly, the copying of records (master copy, usage copy, mini copy) is given in subsection "10.3. Scanning Techniques". There has been a growth in the number of organizations that digitize their archives in Turkey in recent years. This information can be explanatory and guiding for organizations and system designers. However, rapidly developing technology brings new formats and new techniques. Therefore, this information must be updated from time to time. For instance, PDF-A format stated in MoReq2 (M6.5.3) has become widespread in recent years. According to the AIIM's (2009) study, 56\% of scanned documents have been switched from the traditional TIFF format, with a $12 \%$ adoption of PDF-A, which is a more suitable archive format. 
Search, retrieval and presentation: When evaluating the two standards in terms of search, retrieval and presentation, they both have common requirements in basic issues such as use of full text and/or metadata, generating combinations, controlled vocabulary, advanced search and retrieval of search results without any further operation (TS 4.2/M8.1). As seen under the subsection "8.1: Search and Retrieval", when defining a requirement in MoReq2, reference is made to the respective standards, if any. For instance, in requirements M8.1.17 and M8.1.18, when a thesaurus is included in ERMS the standards which must be followed (ISO 2788, ISO 5964) are also stated. As seen in requirements M8.1.21, M8.1.22 and M8.1.29 of MoReq2, advanced search functions are explained in detail with samples. Similarly, print options are extensively dealt with (M8.3.7- M8.3.16), and some handy requirements are listed. On the other hand, TS (4.4) presents three requirements for print options. Although explanations in MoReq2 seem to be more detailed, they turn out to be useful in avoiding problems which may appear in time.

Metadata scheme: Metadata scheme and XML is one of the strong features of MoReq2. Taking into account metadata requirements, several basic requirements are in common, such as limitations concerning metadata elements (M12.2.1/TS11.1.a), functions of metadata and ERMS (M12.2.2/TS11.1.b), formats which metadata elements must support (M12.2.3/TS11.1.c). However, details in the requirements of MoReq2 (M12.2.9, M12.2.16) and references to the standards (M12.2.7, M8.1.17, M8.1.18) come to the fore as well.

Metadata elements are the proof of the life-cycle of records. Therefore, they must be formed with great care. Metadata requirements of organizations can vary as well. However, a standard must be guiding and explanatory in terms of both content and presentation. MoReq2, Appendix 9 [17] presents the metadata elements in a very practical format (See Figure 1). Even this document can be an important guide for the system designers. Information concerning the location of metadata in the system, how it will be defined, under what conditions it will be used, the changes which can be made, and values which can be defined is given in a systematic and clear manner. Such a structure is important with regard to deciding and describing the metadata required.

93 metadata elements are defined in TS "Section III: Metadata Scheme". Metadata is composed solely of metadata name, short definition and short explanations below some of them. There is no systematic structure. Given that electronic records management in Turkey does not go back very far, it is needless to say that there is a lack of information and know-how concerning metadata in both public and private organizations in Turkey. Therefore, TS is a quite significant reference source. As noted earlier, evaluating all metadata elements individually is not included within the scope of this study. However, it is considered that the metadata structure of MoReq2 in terms of presentation and scope could be an important reference model for the improvement of TS. Thus, it will be possible to present organizations with a more proper and standard structure to select their metadata elements. 


\begin{tabular}{|c|c|c|c|c|}
\hline & Obligation: & Mandatory & Occurs: & Once \\
\hline Definition: & \multicolumn{4}{|c|}{ A name given to a record type. } \\
\hline Populated: & \multicolumn{4}{|c|}{ Manually entered when the entity is created. } \\
\hline Source: & \multicolumn{4}{|l|}{ User. } \\
\hline Default: & \multicolumn{4}{|l|}{ None. } \\
\hline $\begin{array}{l}\text { Use } \\
\text { conditions: }\end{array}$ & \multicolumn{4}{|c|}{$\begin{array}{l}\text { Can be changed by an administrative role or by users who } \\
\text { appropriate access rights. } \\
\text { Must be unique. }\end{array}$} \\
\hline Comment: & \multicolumn{4}{|l|}{ No comment. } \\
\hline Requirements: & \multicolumn{4}{|l|}{5.1 .15} \\
\hline
\end{tabular}

Fig. 1. MoReq2 example of metadata scheme [17]

\section{Conclusion and Recommendations}

Developed in context of e-government work, TS is one of the most significant steps in electronic records management in Turkey. It has filled an important gap as a guide for organizations and companies producing software. The rapid development in technologies and the changing conditions make it necessary for standards to be improved. Established as a national standard for the first time, it is quite correct and natural for TS to present minimum requirements at the first stage. However, when the purpose is to generalize the use of standards, taking into account the diversification of requirements of the organizations, TS has to be further developed. One of the important issues to develop TS in terms of terminology is building a glossary section. Giving explanations concerning the subjects in sections, if deemed necessary, will ensure the integrity of the document and will make it easy to use. Providing definitions of the requirements concerning access control and security must not leave any ambiguity in terms of system security and management. Particularly, to define the responsibilities of the system administrator more clearly and in more detail is important for the development of TS in terms of its terminology. At the same time, the classification of the authorizations of user roles and presenting it in a table like in MoReq2, [16] will make it easy for the roles to be defined. Arranging audit trials, presenting more detailed requirements related to the records and adding more requirements concerning the storage of the data, need to be taken into consideration as well.

Widening the scope of retention and disposal requirements will pave the way for the control of this operation, which is of crucial importance for the organizations. Particularly, clarifying the responsibilities of the records manager and system administrator, and adding requirements for disposal process with metadata and audit trial, are needed. Furthermore, requirements which should be included concerning transform and export can be taken into consideration particularly to prevent data losses which may occur in the case of merging organizations. 
Expanding the scope of metadata and audit trail requirements concerning registration of records will have an effect on the long term preservation of records. Furthermore, an extensive list of possible electronic record types can be established, and record types like blogs, wikis, instant messaging systems, etc. can also be taken into consideration.

E-mails are one of the fundamental tools of communication for some organizations. It is obvious that TS needs to be reviewed in terms of inclusion of e-mails in the system and providing access to the records components by defining them. The questions of what components of e-mail (attachment, message, etc.) will be defined and how, their classification, definition of their metadata, providing access for the attachments as well as the messages can be dealt with in more detail.

Operations concerning the digitization of records may be the field where other standards are also referred to the most. The operations performed in this process for long term preservation and access of the records and the formats used is of great importance. We believe that tables on file formats in TS are useful for many users. However, these kinds of formats develop constantly and new products are generated. In this context, reviewing sections on file formats will be useful for the adaptation to the new technologies.

For TS, it is possible to express the searching options in a clear manner. It will be useful to add guiding requirements for using a controlled vocabulary or thesaurus for "subject" searching, which is an important component for the records in Turkish. Furthermore, the existing requirements can also be extended in order to develop print options during the system installation.

Metadata elements are the basic management elements of an ERMS. A welldefined metadata scheme is important for the proper operation of the system. Converting the metadata in the TS metadata scheme into a more systematic and explanatory format will be useful for both users and system designers, and will contribute to the compliance of records with the standards. The status, scope, terms of conditions, values of the metadata elements and whether any alterations need to be made for these elements have to be included in TS, with their explanations. Furthermore, a systematic metadata scheme, which will be established by taking the MoReq2 metadata scheme as a sample, will be useful for the ease of use of TS. Working on the establishment of an XML scheme, which can be used for the transfer of data between systems, will be an important step for the improvement of the standard.

It can be said that the main reason why there are more differences between TS and MoReq2 than similarities is that their purposes and the groups which they address are different. However, this is not an obstacle to improving TS by taking MoReq2 as reference. MoReq 2 has already been prepared as a reference document and designed to be a superstructure. As it has not been prepared considering solely a specific organization or country, it addresses a broader user audience. Although it is criticized in terms of its details and cost, it aims to build the best system possible with a content aiming to eliminate the possible problems which may occur in the system, giving explanations and references concerning the issues. Planned to be revised in 2010, MoReq2 sends correct signals to be an important standard to be adopted by many countries in the future. As a candidate country of the European Union, Turkey must take the progress of MoReq2 into consideration and revise its national standard. In this context MoReq2 offers some good options like Chapter 0. Turkey should con- 
sider creating a Chapter 0 or update and revise TS by mapping MoReq 2 in terms of its structure and requirements. The pros and cons of these alternatives should be discussed and examined in detail in future studies.

Indeed, standards cannot be a stand-alone solution to all problems. However, raising awareness in records management, which is a very new subject for Turkey, filling the gap in the field in terms of information and experiences, developing and generalizing the use of standards is of great importance in order to act in parallel to future technological developments. It is clear that it will be vital to improve and update TS given that all of the governmental institutions will have adopted their electronic records management system in accordance with TS [26]. This process must be undertaken not only by record managers but with the joint experience and know-how of actors in various fields, such as organization managers, users, data processing experts, computer engineers. Thus, participation from all fields will be achieved for the developments, and it will be possible to establish ERMS in Turkey on firm ground. These developments will contribute to an enhancement of e-government, e-business services.

Comparing and evaluating all metadata elements individually is not within the scope of this study but can be a guide for more specific studies. A detailed study on metadata schemes is being carried out within the scope of TS, MoReq2 and NOARK5 (Norwegian standard for ERMS) with the support of Oslo University College and the Research Council of Norway. It is planned that the study will be completed in April 2010. It is believed that this and similar studies will provide significant contributions for building awareness on ERMS and for the development of better applications.

Acknowledgments. This study was carried out as the first stage of a research entitled "A Comparative Study of Electronic Records and Metadata Schemas in Norway and Turkey", which is supported by the YGGDRASIL scholarship, granted by the Research Council of Norway. We would like to thank the Research Council of Norway and Oslo University College for their support.

\section{References}

1. AIIM: Industry Watch (2009), http: / /www .aiim.org/infonomics / still-playing-catchup-with-paper.aspx

2. Public Record Office: E-government Policy Framework for Electronic Records Management (2001), http: / / www . nationalarchives.gov.uk/documents / egov_framework.pdf

3. Screene, L.: How Prepared are Public Bodies for the Implementation of the UK Freedom of Information ACT. Records Management Journal 15, 34-42 (2005)

4. Wamukoya, J.: Records and Archives as a Basis for Good Government: Implications and Challenges for Records Managers and Archivists in Africa. Records Management Journal 10, 23-33 (2000)

5. Kampffmeyer, U.: Records Management \& MoReq (2009), http://www.projectconsult.net/Files/20091006_InnovaDoc_Barcelona_Kff_Show.pptx

6. Waalwijk, H.: How Normal is Normalisation ? (2005), http://ec.europa.eu/transparency/archival_policy/dlm_forum/ doc/14bis_waalwijk.pdf 
7. MoReq: Model Requirements for the Management of Electronic Records. European Commission, Office for Official Publications of the European Communities (2001), http: / / www . cornwell.co.uk/moreqdocs/moreq.pdf

8. ISO/IEC Information Centre: Standards and Regulations (2008), http: / /www.standardsinfo.net/info/livelink/fetch/2000/ 148478/6301438/standards_regulations.html

9. Stephens, D.O.: International Standards and Best Practices in RIM. Information Management Journal (2000), http://findarticles.com/p/articles/mi_qa3937/ is_200004/ai_n8887526/

10. Pember, M.: Sorting Out the Standards: What Every Records and Information Professional Should Know. Records Management Journal 16, 21-33 (2006)

11. ARMA: ARMA International (2009), http: / / www . arma.org/standards/index. cfm

12. Hofman, H.: Developments in ISO Standards for Recordkeeping. In: DLM Forum Conference (2005), http://ec.europa.eu/transparency/archival_policy/ dlm_forum/doc/17bis_hofman.pdf

13. ISO: ISO 15489-1: Information and Documentation - Records Management. International Organization for Standardisation (2001), http: / /www . iso . org

14. Brübach, N.: International Standard for Archives and Records Management ISO 15489. In: Proceedings of the DLM-Forum 2002, @ ccess and Preservation of Electronic Information: Best Practices and Solutions, Barcelona, May 6-8 (2002), http: / / ec.europa.eu/transparency/archival_policy/dlm_forum/ doc / dlm-proceed2 002 .pdf (retrieved December 29, 2009)

15. Köhler-Krüner, H.: MoReq2 (2009), http://www.kompetencefabrikken.dk/fileadmin/ressourcer/ filer/Moreq2_Denmark.pdf

16. MoReq2: Model Requirements for the Management of Electronic Records. MoReq2 Specifications. European Commision, Bruxelles-Luxembourg (2008), http: / /www. dlmforum.eu/ index . php?option=com_jotloader\&view=categories\&cid= 10_f56391a0c9ea9456bf24e80b514f5dda\&Itemid=37\&lang=en

17. MoReq2: Model Requirements for the Management of Electronic Records. MoReq2 Specifications. Appendix 9 to the Moreq2 specification: Metadata model. European Commision, Bruxelles-Luxembourg (2008b), http: / /www. dlmforum. eu / index . php?option=com_jotloader\&view=categories\&cid= 10_f56391a0c9ea9456bf24e80b514f5dda\&Itemid=37\&lang=en

18. NOARK 5: Standard for electronic Archive (2005), http://www.arkivverket.no/noark-5/noark_5_20.pdf

19. DLM Forum: DLM Forum (2009), http: / / www. dlmforum. eu/index.php

20. Garde, J.: Essential MoReq2. DLM Forum Members Meeting. Czech Republic, Prague, April 21-22 (2009), http: / / www . nacr.cz/dlm/presentations/garde.pdf

21. Wilhelm, P.: EDRMS Standards - A Critical Evaluation of The Benefits of Superseding National Standards With European Models Focusing on TNA 2002 Replacement by MoReq2. School of Computing, Engineering and Information Sciences Northumbria University (2008), http: / / www . moreq2 . eu/papers-etc

22. DLM Forum: Invitation to Tender for MoReq2 Work program 2010 (2009), http: / /www.dlmforum.eu / index.php?option=com_jotloader\&view=c ategories\&cid=34_2f8a6e502e2dd8ea6b7f2e7a79626230\&Itemid= $113 \&$ lang $=$ en 
23. Wilhelm, P.: An Evaluation of Moreq2 In The Context of National EDRMS Standard Developments in The UK and Europe. Records Management Journal 19, 117-133 (2009)

24. Henttonen, P.: A Comparison of MoReq and SÄHKE Metadata and Functional Requirements. Records Management Journal 19, 26-36 (2009)

25. TS: TS13298 Information and Documentation-Electronic Records Management. Institute of Turkish Standards (2007), http: / / www. tse.org.tr

26. Elektronik Belge Standartları Başbakanlık Genelgesi, T.C. Resmi Gazete (26938, 18 Temmuz (2008)

27. Powell, R.R.: Recent Trends in Research: A Methodological Essay. Library and Information Science Research 21, 91-119 (1999)

28. Cole, M., Avison, D.: The Potential of Hermeneutics in Information System Research. European Journal of Information System 16, 820-833 (2007)

\section{Appendix}

Table of sections and subsections analysed in MoReq2 and TS13298

\begin{tabular}{|c|c|}
\hline MoReq2 & TS13298 \\
\hline $\begin{array}{l}\text { 4. Controls and security } \\
\text { 4.1. Access } \\
\text { 4.2. Audit trails } \\
\text { 4.3. Backup and recovery } \\
\text { 4.4. Vital records }\end{array}$ & $\begin{array}{l}\text { 5. Access control and security } \\
\text { 5.2. Access rights } \\
\text { 5.3. User profiles } \\
\text { 5.4. User roles } \\
\text { 5.5. User groups } \\
\text { 5.7. Creator and property rights } \\
\text { 5.9. Audit } \\
\text { 6. System design and administration } \\
\text { 6.4. Storage of data } \\
\text { 8. Document management } \\
\text { 8.5. Storage/Backup } \\
\end{array}$ \\
\hline $\begin{array}{l}\text { 5. Retention and disposition } \\
\text { 5.1. Retention and disposition } \\
\text { schedules } \\
\text { 5.3. Transfer, export and } \\
\text { destruction }\end{array}$ & $\begin{array}{l}\text { 2. Retention } \\
\text { 2.1. General rules } \\
\text { 2.2. Hierarchy of classification } \\
\text { 2.3. Criteria of retention } \\
\text { 2.4. Retention duration } \\
\text { 2.5. Definitions of disposition } \\
\text { process }\end{array}$ \\
\hline $\begin{array}{l}\text { 6. Capturing and declaring records } \\
\text { 6.1. Capture } \\
\text { 6.3.E-mail management } \\
\text { 6.5. Scanning and imaging }\end{array}$ & $\begin{array}{l}\text { 3. Capturing of electronic records } \\
\text { 3.1. General rules } \\
\text { 3.4. Capturing e-mails } \\
\text { 10. Digital scanning systems } \\
\text { 10.3. Scanning techniques } \\
\text { 10.4. Resolution } \\
\text { 10.5. Color } \\
\text { 10.9. File formats } \\
\end{array}$ \\
\hline $\begin{array}{l}\text { 8. Searching, retrieval and presentation } \\
\text { 8.1. Search and retrieval } \\
\text { 8.3. Presentation: Printing } \\
\end{array}$ & $\begin{array}{l}\text { 4. ERMS usage requirements } \\
\text { 4.2. Searching } \\
\text { 4.4. Printing }\end{array}$ \\
\hline $\begin{array}{l}\text { 12. Metadata scheme } \\
\begin{array}{l}12.2 . \quad \text { General metadata } \\
\text { requirements }\end{array}\end{array}$ & $\begin{array}{l}\text { 11. Metadata elements } \\
\text { 11.1. General rules }\end{array}$ \\
\hline
\end{tabular}

